\title{
A biomechanical and optimality-based derivation of prey-size dependencies in planktonic prey selection and ingestion rates
}

\author{
Kai W. Wirtz* \\ Helmholtz-Zentrum Geesthacht, Institute for Coastal Research, 21501 Geesthacht, Germany
}

\begin{abstract}
In their natural environment, planktonic grazers encounter considerable size variation in prey species. As a quantitative representation of feeding on diverse prey, theoretical studies use feeding kernels to describe grazing intensity as a function of body size, a factor that is a strongly discriminative property of prey. However, kernel functions are in general based on heuristic and poorly tested choices, lack an unequivocal definition, and are often based on experiments using mono-specific prey rather than a broad prey spectrum as found in nature. The work reported here seeks to fill these theoretical gaps by exploring the distinction between the ingestion kernel and the selection kernel. While the ingestion kernel describes which size classes can be potentially used by a consumer, the selection kernel depicts the actual size-dependent grazing on prey assemblages. Simple biomechanical laws show that the ingestion kernel takes a log-normal shape with a universal width $(1 / \sqrt{3}$ in log-diameter-space). Experimental data from the literature supported the predicted constant value of the ingestible logarithmic size range across plankton taxa. The selection kernel resolves behavioral modifications during the capture process. In particular, the inverse of the variable kernel width defines consumer selectivity as a quantitative behavioral trait. Small kernel width, and thus large selectivity values, represents an optimization by consumers towards high food availability. Optimality in selectivity was tested using observations on copepod grazing. Integral grazing rates that incorporate prey diversity and adaptive consumer selectivity are demonstrated to provide a sound mechanistic basis for size-based plankton models.
\end{abstract}

KEY WORDS: Zooplankton - Selectivity · Feeding kernel · Trophic niche $\cdot$ Feeding breadth · Optimal foraging

\section{INTRODUCTION}

Body sizes of predator and prey are fundamental traits in the theoretical and empirical study of aquatic food webs (Brooks \& Dodson 1965, Woodward et al. 2005). Size in part defines a taxon's trophic position because larger taxa usually consume smaller taxa. Trophic size relations can be expressed by optimal prey size which is a function of both predator size and feeding mode (Hansen et al. 1994, Wirtz 2011). A mismatch between actual prey size and optimal prey size reduces ingestion rate. Dependence of ingestion rate on prey size is described by the feeding kernel function, which is generally a unimodal function that determines the edible part of the preysize spectrum that is grazed and the corresponding rate at which grazing can occur. Both the functional form of feeding kernels and the implied diet breadth affect the results of size-based foraging models; kernel shape controls the transfer of mass and energy within model food webs, affects food web stability, and influences the extent of coexistence among (model) species (Troost et al. 2008, Fuchs \& Franks 2010). 
Following the pioneer works of Moloney \& Field (1991) and Armstrong (2003), size as a trait is increasingly resolved within plankton models (e.g. Baird 2010, Fuchs \& Franks 2010, Zhou et al. 2010, Banas 2011). Spectral or multi-species size-based models use explicit or implicit assumptions on the shape of the feeding kernel. Modeling either starts from empirical rules-of-thumb (Maury et al. 2007, Petchey et al. 2008, Williams et al. 2010) or from kernel shape functions, such as Gaussian (Armstrong 2003, Troost et al. 2008, Banas 2011) or Laplacian functions (Fuchs \& Franks 2010), which until now lack thorough empirical testing and mechanistic explanations. Only recently, Visser \& Fiksen (2013) proposed re-routing size-based feeding models towards biomechanical and evolutionarily sound principles, and assembled process-oriented formulations such as prey size dependencies of capture probability or energy content per item. However, Visser \& Fiksen's resulting feeding kernels prescribe a relatively large diet breadth that even under food-replete and thus, selective grazing conditions spans 2 orders of magnitude, in contrast to the considerably smaller diet breadths observed in situ for selective copepod grazing (Wilson 1973, Richman et al. 1977, Pagano et al. 2003).

Most empirical evidence on feeding kernels is derived from experimental results that use monospecific prey with low size diversity. Indeed, few studies have provided preference patterns of planktonic consumers that face a wide spectrum of prey sizes (Rothhaupt 1990, Katechakis et al. 2004). However, serial experiments at different specific prey size differ fundamentally from grazing experiments using assemblages of prey species. Both types of experiments can be related to a feeding kernel, but their interpretation should not be confounded, in particular in the course of model development. Mono-specific grazing experiments, even if conducted in parallel for different prey populations, describe the potential to ingest a prey particle of a specific size. This case refers to a biomechanical problem related to the morphology of predators and prey and to an understanding of how specific food items are ingested (Wirtz 2013). The second case (prey assemblages) categorizes observations of the actual ingestion rate in the presence of diverse particles. These ingestion patterns predominantly reflect consumer behavior and are linked to the problem of why one type of food is preferred over others. Selective grazing in the natural case of a broader prey size spectrum plays an important role in the conceptual explanation of variable feeding relations (Sommer \& Stibor 2002), as also reflected by the usage of selectivity coefficients (Manly et al. 1972, Chesson 1983), but so far has not been defined as a quantitative trait.

One goal of this study is to develop a theory that distinguishes between 2 distinct feeding kernels, one for ingestion and one for selection. Both kernel formulations should rely on biomechanical or evolutionarily sound constraints. The theory therefore starts from biophysical laws underlying prey-size-dependent ingestion of mono-specific prey. The biomechanical derivation of the generic ingestion kernel will-after validation-provide the framework for the second goal of the study, which is to develop and test an operational definition of size selectivity. This definition of size selectivity should translate behavioral modification of diet breadths into a quantitative form that facilitates (1) the interpretation of observed changes in trophic interactions, (2) the development of trait databases (Litchman et al. 2010), and (3) the implementation of size-based models.

\section{MATERIAL AND METHODS}

\section{Ingestion kernel}

The maximal amount of ingested prey mass per unit of time and predator mass is commonly referred to as $I_{\max }$. The maximum ingestion rate $I_{\max }$ is limited by internal constraints in handling, digestion, and evacuation, which partially derive from size-related biophysics. A reference point of such constraints is the optimal prey size. This target size is determined by the consumer's uptake apparatus, through morphological factors such as mandible length or gut diameter. When actual prey size exceeds optimal prey size, $I_{\max }$ decreases, corresponding to a prolongation in processing time. Mechanical pre-processing (e.g. crushing and cutting), as well as additional biochemical digestive treatment and clogging in the gut, may slow down particle intake and evacuation, respectively. Biomechanical friction in food processing can be assumed to increase with both prey size, as also observed previously (Swift \& Fedorenko 1975, Thompson 1975, Pastorok 1981), and with the processing time itself. Larger prey increases pre-processing efforts, digestion times, and delay probability. Similarly, when capture, handling, and digestion already take relatively long, delays will become longer as well. Under these 2 assumptions, the prey size dependency in $I_{\max }$ can be shown to follow a lognormal function (see Appendix A-I):

$$
I_{\max }=I_{\max }^{*} \cdot \mathrm{e}^{-3 / 2\left(\ell-\ell_{\mathrm{opt}}\right)^{2}}
$$


Table 1. Auxiliary functions and model parameters. Prey size variables are listed in their logarithmic and absolute (in parentheses) form

\begin{tabular}{|ll|}
\hline Symbol & Description \\
\hline$f_{\text {sel }}$ & Selection kernel (in the log-size space) \\
$f_{\text {sel, }}$ & Rectangular selection kernel \\
$I_{\max }$ & Maximum ingestion rate \\
$I_{\max }^{*}$ & $I_{\max }$ of ideal food \\
$\bar{I}_{\max }$ & Consumer mean of $I_{\max }$ \\
$P_{\text {tot }}$ & Total prey biomass \\
$P_{\ell}$ & Prey mass distribution \\
$\ell(D)$ & Prey size \\
$\tilde{\ell}$ & Average (log) prey size \\
$\ell_{\text {opt }}\left(D_{\mathrm{opt}}\right)$ & Optimal prey size \\
$\sigma_{\ell}^{2}$ & Variance of (log) prey size \\
$S$ & Selectivity (inverse width of $\left.f_{\text {sel }}\right)$ \\
$S_{\mathrm{w}}$ & Inverse width of rectangular kernel \\
$\tau$ & Food processing time \\
$\tau_{\min }$ & Processing time for optimal prey \\
\hline
\end{tabular}

In this work, body size is given in terms of the logarithmic equivalent spherical diameter, $\ell=\log (\mathrm{ESD} /$ $\mathrm{ESD}_{0}$ ), with arbitrary basic size unit (here $\mathrm{ESD}_{0}=$ $1 \mu \mathrm{m})$. The logarithmic form is often used both in empirical (e.g. Hansen et al. 1994, Katechakis et al. 2004) and modeling (e.g. Armstrong 2003, Fuchs \& Franks 2010) studies to capture high variability in absolute prey size. Here, it is merely a consequence of the 2 biophysical assumptions made above. The log-normal kernel (Eq. 1) furthermore provides an explicit value of the kernel width $(1 / \sqrt{3}$ in $\log$-ESDspace) and of the central kernel position $\left(I_{\max }(\ell)=\right.$ $I_{\text {max }}^{*}$ at $\ell=\ell_{\text {opt }}$, the logarithmic optimal prey size, see also Table 1 for definitions of auxiliary functions and model parameters).

\section{Size selectivity}

The ingestion kernel $I_{\max }(\ell)$ describes the preysize-dependent grazing rate under replete food conditions provided all prey items are of the same size. The function, however, does not express the actually ingested spectrum when the consumer selects among a more natural prey assemblage with a broader distribution of size. Planktonic consumers possess a variety of ways of adjusting their feeding behavior. They may swim or wait (Kiørboe \& Saiz 1995, Boenigk \& Arndt 2002), modify the speed of the feeding current (Frost 1972, Visser et al. 2009, Pahlow \& Prowe 2010), produce prey-specific toxins (Helmholz et al. 2010), switch between different feeding types (Saiz \& Kiørboe 1995), or change parti- cle clearance rate as a function of local density of food items (Jeschke \& Tollrian 2005, Kratina et al. 2009).

Behavioral plasticity shrinks the overall spectrum of potentially available, ingestible, and digestible prey towards a specific subrange. The relative amount of food particles belonging to this subrange is then higher in the consumer's gut than in the surrounding environment, which in the terminology of Ivlev (1961) or Williams \& Marshall (1938) is called a large 'foraging ratio' or a positive 'electivity'. Size selectivity originates either from the biomechanics of the feeding apparatus or from active choices based on chemical, fluid-mechanical or optical perception, or from interactions among these factors (Verity 1991). Size selectivity in the cladocerans, for example, may follow from gape modulation, while in rotifers selectivity occurs through pseudotrochal screening or reverse ciliary beating (Pagano 2008). Also, copepod grazing shows much larger diversity in rejecting filtered items than expressed by a simple geometric by-pass model based on inter-setular distance (Paffenhöfer 1984, DeMott 1988).

From an evolutionary perspective, the size dependencies of internal and external processing have to match each other. Selective clearance activity $f_{\text {sel }}$ should therefore approximate a uni-modal function with a maximum at or close to the optimal prey size $\ell_{\text {opt }}$ introduced for internal processing. Like $I_{\text {max }}\left(\ell, \ell_{\text {opt }}\right), f_{\text {sel }}$ will be roughly symmetric around $\ell_{\text {opt }}$ in log-space since biomechanical constraints slow down post-capture processing equally for smaller and larger prey, as already discussed above. A significant clearance preference towards one direction, equivalent to a strongly skewed selection kernel $f_{\text {sel }}$, would leave processing capabilities in one prey-size direction unexploited. Contrary to $I_{\max }(\ell)$, however, the width of the selection kernel function needs to be flexible, depending on the food concentration.

\section{Idealized rectangular kernel and its smoothing}

The simplest symmetric feeding kernel is a rectangular function with constant, non-zero value in a range centered at $\ell_{\text {opt }}$ and having a variable width $2 / S_{\mathrm{w}}$ (cf. idealized filtrator spectrum with uniform filter porosity in Fig. 1 of Hansen et al. 1994):

$f_{\mathrm{sel}, \mathrm{w}}=\frac{s_{\mathrm{w}}}{2} f_{\mathrm{sel}, \mathrm{w}}^{\prime}$ with $f_{\mathrm{sel,w}}^{\prime}=\left\{\begin{array}{l}1: \text { if }\left|\ell-\ell_{\mathrm{opt}}\right| \leq 1 / s_{\mathrm{w}} \\ 0: \text { else }\end{array}\right.$

$f_{\text {sel,w }}$ is normalized such that its integral over prey size yields 1 , (i.e. $\int_{-\infty}^{+\infty} f_{\mathrm{sel}, \mathrm{w}} \mathrm{d} \ell=1$ ). It includes the 
Boolean variable $f_{\text {sel,w }}^{\prime}$ which describes an instantaneous, single-item related decision. A rectangular kernel $f_{\text {sel,w }}$, though, is difficult to realize on the population or community level, or over longer feeding periods. A sharp control ability requires that only prey items with $\ell$ lower than $\ell_{\mathrm{opt}}+1 / s_{\mathrm{w}}$ are captured, whereas those with slightly different size must be entirely dismissed. When the kernel represents the selective behavior of populations or communities, various additional factors blur the realized kernel shape. These include variability in body size and $\ell_{\text {opt }}$ of the predators, their discriminating properties (e.g. mesh sizes, antenna dimensions), non-size-related prey properties (e.g. motility, nutritious quality), or physico-chemical-biological features of the microenvironments (e.g. transparency, turbulence, predator abundance). These factors smooth the idealized rectangular function towards a Gaussian type shape.

$$
f_{\text {sel }}=\sqrt{\frac{s}{\pi} f_{\text {sel }}^{\prime}} \text { with } f_{\text {sel }}^{\prime}=\mathrm{e}^{-s\left(\ell-\ell_{\text {opt }}\right)^{2}}
$$

Although a higher order Gaussian could be a better surrogate of the rectangular kernel, the second order form facilitates analytical calculations (see Appendices A-II and A-III) and, because of the mathematical similarity to the ingestion kernel, mechanistic arguments for its support can again be sought. The functional equivalence to the ingestion kernel $I_{\max }(\ell)$ simulates purely biomechanical particle selection in the absence of behavioral changes. Perception prob- ability of particles will increase with their size in proportion to particle surface or cross-sectional area $\left(\propto D^{2}\right)$. If, on the other hand, it already takes a long time to capture and kill a large prey, a marginally greater prey will need an even greater effort, which in turn induces an exponential decay in the capture probability $\left(\propto \mathrm{e}^{-\delta^{\prime} D}\right)$ in resemblance of Eqs. (A3) \& (A4) in Appendix A-I. Taking both arguments together, the result is a log-normal-like functional shape of capture probability, in analogy to the sizedependency of $I_{\max }(\ell)$ in Eq. (1).

The inverse kernel width in Eq. (3) is here introduced as the quantitative trait selectivity $s$. A value of $s$ close to zero describes unselective grazing on a broad food-size spectrum, while larger values emulate a narrowing of the spectrum (cf. Fig. 1).

\section{Selectivity as determinant of food quantity and ingestion rate}

The value of the selectivity $s$ may vary between different feeding types, between consumer species, or in time within an individual consumer. These variations often depend on food diversity and availability (Jürgens \& DeMott 1995, Broglio et al. 2004, Katechakis et al. 2004). For calculating such variations in $s$ using an optimality approach, we need to first quantify how the variations in $s$ propagate to various aspects of the grazing kinetics.
A

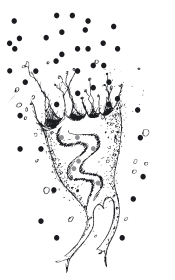

Uni-size prey
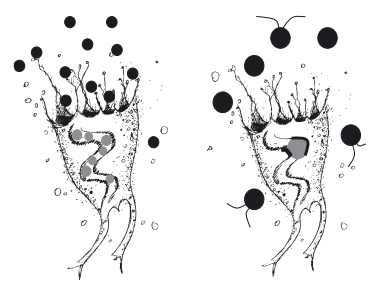

B Multi-size assemblage
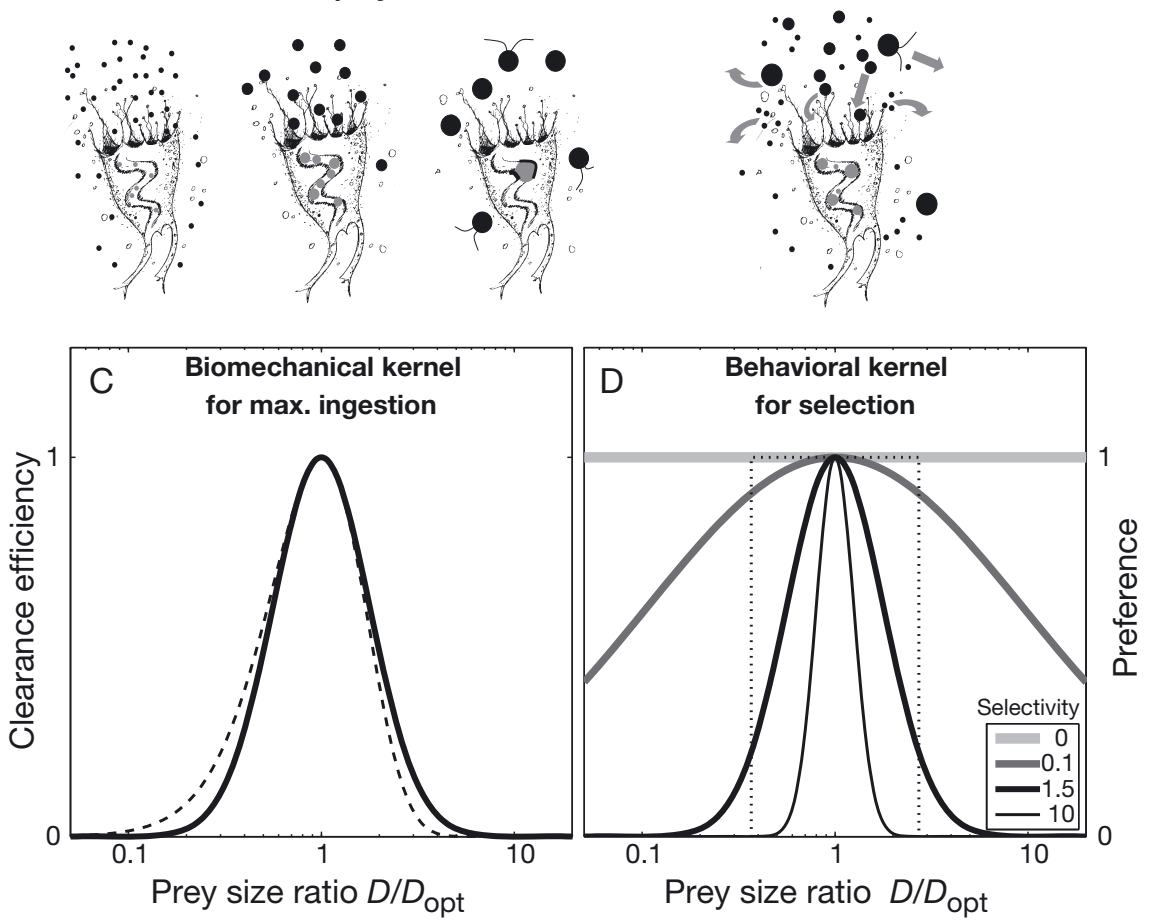

Fig. 1. Top: Ingestion by a suspension feeder facing (A) mono-size prey or (B) a multi-size assemblage. Bottom: (C) Ingestion kernel $I_{\max }$ over prey size. The original skewed version (Eq. A5 in Appendix A-1; dashed line) is compared to its nonskewed, log-normal approximation (Eq. 1; solid line). (D) Behavioral feeding kernels $f_{\text {sel }}^{\prime}$ are displayed for different values of selectivity $s$. Having same mean and variance values, the rectangular kernel $f_{\text {sel,w }}^{\prime}$ with half width $s_{\mathrm{w}}=1$ (dotted line) corresponds to the reference lognormal kernel at selectivity $s=3 / 2$ (thick black line). The latter function equals the biomechanically derived ingestion kernel in (C) 
Similar to the concept of effective food concentration used by Vanderploeg \& Scavia (1979), the average food harvest $P$ results from the overlay and integration of available food items and the selection kernel. As shown in Appendix A-II, captured and ingested biomass $P(s)$ declines with increasing selectivity,

$$
P(s)=\frac{P_{\text {tot }}}{\sqrt{1+2 s \sigma_{\ell}^{2}}} e^{-\frac{s\left(\ell_{\mathrm{opt}}-\tilde{\ell}\right)^{2}}{1+2 s \sigma_{\ell}^{2}}}
$$

where a log-normal prey size distribution with mean $\tilde{\ell}$ and variance $\sigma_{\ell}^{2}$ has been assumed. More complicated distribution forms including discrete multispecies assemblages can be treated analogously (see Supplement S-I at www.int-res.com/articles/suppl/ m507p081_supp.pdf).

Eq. (4) elucidates the food gain of having a large feeding width. Under a mismatch of $\ell_{\text {opt }}$ and $\tilde{\ell}_{\text {, }}$ harvest rapidly declines. In this scenario only an 'extreme' generalist behavior, e.g. with $s<1$, can ensure an adequate food supply provided that the differences between $\ell_{\text {opt }}$ and $\tilde{\ell}$ remain moderate (Fig. 2C). A broader prey size spectrum (larger $\sigma_{\ell}^{2}$ ) increases the harvest. If, however, the kernel centre matches the density peak of the prey distribution $\left(\ell_{\text {opt }} \approx \tilde{\ell}\right)$, increasing size diversity $\sigma_{\ell}^{2}$ lowers the return. But still a generalist strategy with a broader grazing kernel (small value of $s$ in Eq. 4) leads to nearly complete food harvest (Fig. 2D). As a cost of this wider access to food, generalists must face the trade-off of a lowered maximum ingestion rate since decreased $s$ reduces the effective ingestion rate. Generalist predators choose to handle many nonoptimally suited food items, which lowers mean processing rate $\bar{I}_{\max }$ (Appendix A-III; Fig. 2A,B).

$$
\bar{I}_{\max }(s)=\frac{I_{\max }^{*}}{\sqrt{1+\frac{3}{2 s}}}
$$

\section{Data compilation}

Particle clearance rates and ingestion rates dependent on prey size were collected from the literature as listed in Table 2, where the optimal prey size $\left(D_{\text {opt }}\right)$ is also given. For the dinoflagellate Gyrodinium spirale, $D_{\text {opt }}$ has been shifted from the value of $32 \mu \mathrm{m}$ reported by Hansen (1992) to $23 \mu \mathrm{m}$, because the former estimate corresponds to the most easily ingested prey species of the few species used in the experiments, while the corrected estimate provides a better fit to the data as a whole. In the case of scyphomedusae consuming fish larvae (Cowan \& Houde 1993), $D_{\text {opt }}$ was set to $3.6 \mathrm{~mm}$ and reported error bars in prey
Fig. 2. Selection kernel $f_{\text {sel }}$ (red line), when selectivity is low ( $S=$ 1.5: $\mathrm{A}, \mathrm{C})$, or high $(s=15: \mathrm{B}, \mathrm{D})$. $(A, B)$ The value of the mean maximum ingestion rate over the prey size spectrum $\left(\bar{I}_{\max }\right.$, horizontal line) results from an 'inner product' (grey area) of the ingestion kernel (purple area) and $f_{\text {sel }}$. $(\mathrm{C}, \mathrm{D})$ Effective food concentration (grey area) can be understood as an inner product of the prey size distribution $P_{\ell}$ (green area) and $f_{\text {sel }}$
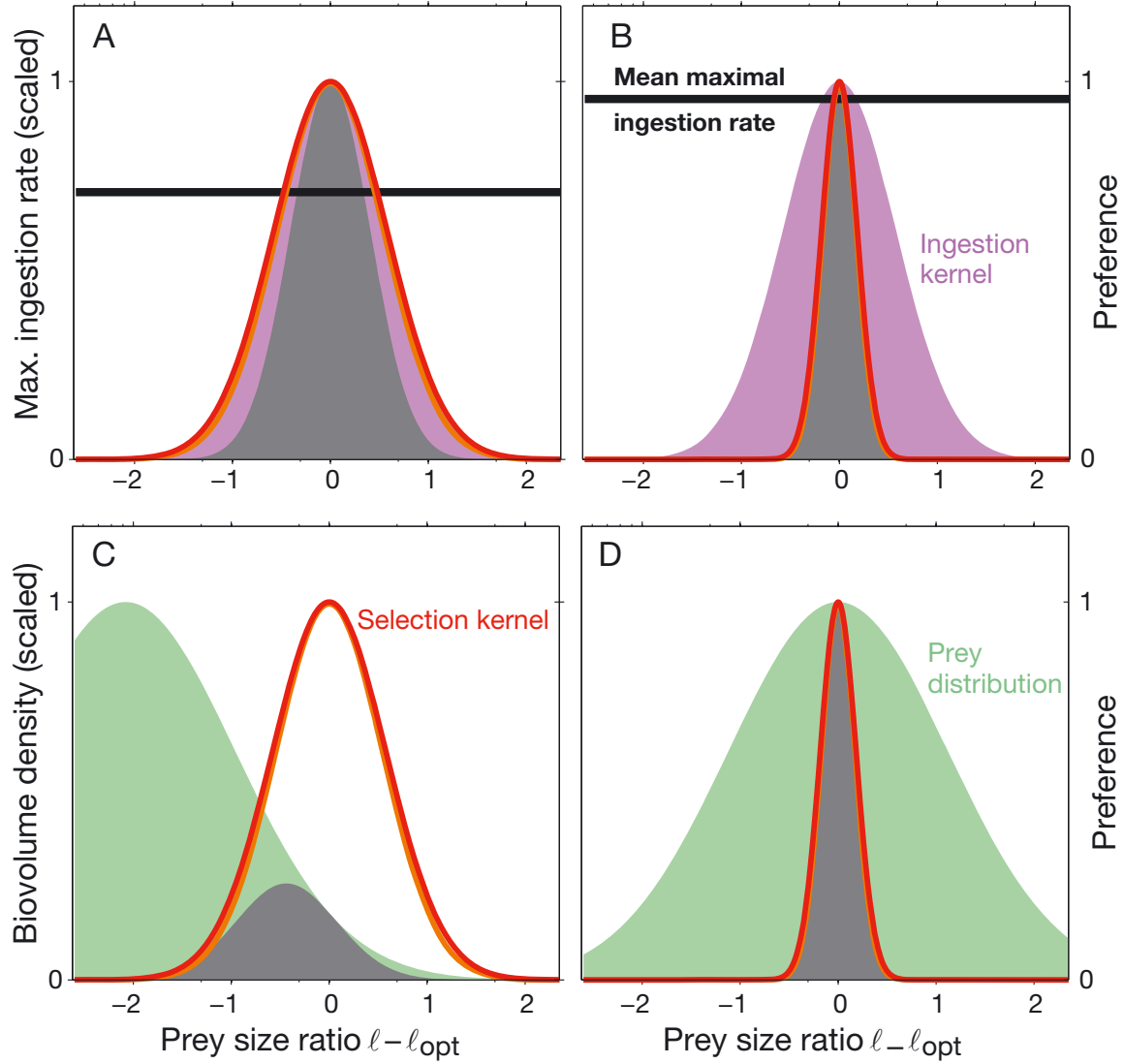
Table 2. Published datasets of size-dependent ingestion or clearance used in this study. ESD: equivalent spherical diameter. -: Data not available

\begin{tabular}{|llccl|}
\hline Consumer species & Food & $\begin{array}{c}\text { Consumer } \\
\text { ESD }(\mu \mathrm{m})\end{array}$ & $\begin{array}{c}\text { Optimal prey } \\
\text { ESD or } D_{\text {opt }}(\mu \mathrm{m})\end{array}$ & Reference \\
\hline Euchaeta elongata & Calanus pacificus & 5000 & 850 & Greene \& Landry (1985) \\
Brachionus plicatilis & Microalgae & 220 & 8 & Hansen et al. (1997) \\
Brachionus rubens & Microalgae & - & 4.8 & Rothhaupt (1990) \\
Gyrodinium spirale & Microalgae & 40 & 23 & Hansen (1992) \\
Chrysaora quinquecirrha & Fish larvae & $4 \times 10^{4}$ & 3600 & Cowan \& Houde (1993) \\
Chrysaora quinquecirrha & Acartia tonsa & - & 2100 & Katechakis et al. (2004) \\
Penilia avirostris & Microalgae & - & 1.5 & Katechakis et al. (2004) \\
Doliolum denticulatum & Microalgae & - & 3.5 & Katechakis et al. (2004) \\
Acartia clausi & Microalgae & - & 9 & Pagano et al. (2003) \\
Acartia clausi & Lake phytoplankton & 360 & 9 & \\
\hline
\end{tabular}

size and mortality were used. However, for the experiments using different stages of Acartia tonsa (Suchman \& Sullivan 1998), no mortality errors were given, and $D_{\text {opt }}$ was shifted to $2.1 \mathrm{~mm}$ because Chrysaora quinquecirrha individuals were on average smaller than those used in the fish larvae experiments $(3.2 \mathrm{~cm}$ vs. $5.5 \mathrm{~cm})$. Horizontal error bars-if not reported in original references - were estimated based on typical size distribution widths of prey populations. Vertical error bars for the experiments of Hansen (1992) and Hansen et al. (1997) were assumed to be equal to the lowest value of standard deviations given by Greene \& Landry (1985) (see Fig. 3, Table 2).

\section{RESULTS AND DISCUSSION}

\section{Logarithmic body size as a fundamental trait}

A primary result of this work is the identification of the logarithmic form of prey size (log ESD) as a key variable for characterizing trophic relations. The logarithmic representation of body size is an outcome of a mechanistic, biophysical approach. It followed from simple geometric assumptions that were first formulated in terms of absolute body size ( $D$ in Appendix A-I). The log form offers a variety of methodological advantages and has therefore been widely used in former size-based analyses or modeling studies. For example, it especially avoids the consistency problem of many symmetric distribution functions based on absolute size that always prescribe a non-zero fraction of particles with negative size (Bruggeman 2009).

Also, size variability within single populations in general produces a log-normal distribution (Pearre 1986). This reflects both general properties of reproduction (e.g. cell division in autotrophs) and size- related mutations and clone diversity, which are all linked to the body volume of the parental/ancestral individual, and thus lead to relative (i.e. proportional to parental body size) instead of absolute changes.

\section{Size- and mode-invariant feeding bell}

The biomechanically derived function $I_{\max }(\ell)$ substantiates the log-normal kernels prescribed in the models of Armstrong (2003) or Banas (2011), but refines these kernels with respect to their widths. The function is here demonstrated to reproduce measured ingestion rates or the transformed clearance rates reasonably well. Fig. 3 shows a high

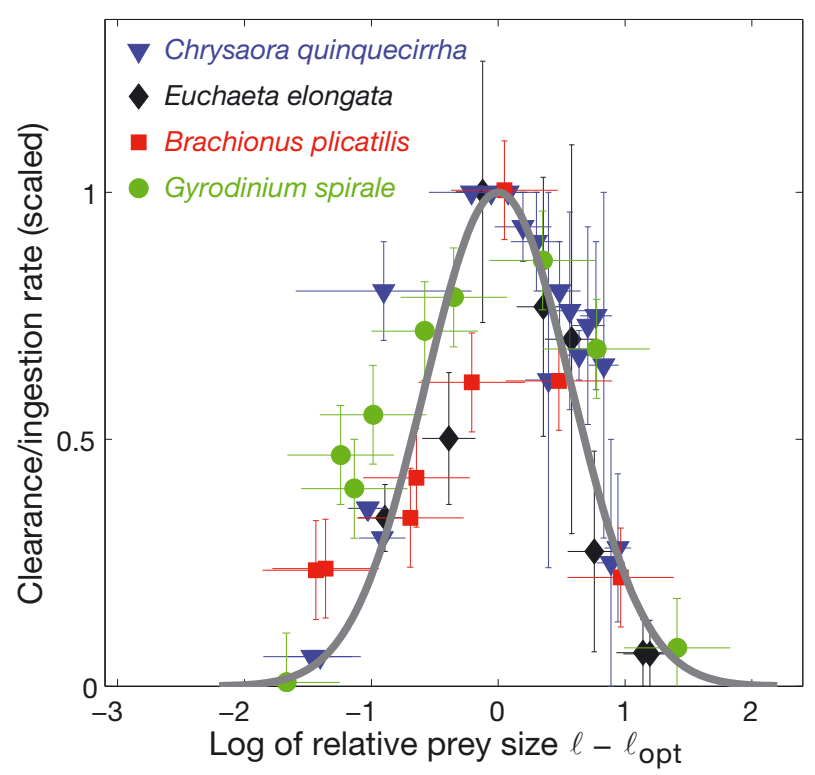

Fig. 3. Maximum ingestion rate $I_{\max }$ as a log-normal function of relative prey size $\left(\ell-\ell_{\text {opt }}\right.$ Eq. 1) (grey curve). Measured clearance/ingestion rates of 4 species with different predation modes (points) are taken from literature sources (see Table 2) and scaled to the maximum value. Error bars: SD 
agreement between theory and observations in several consumer taxa from dinoflagellates to scyphomedusae, the body volumes of which span 6 orders of magnitude (see Table 2). Diversity in feeding types is represented by an ambush tactic (Euchaeta elongata) or palladium feeding (Gyrodinium spirale) to a suspension feeding type (Chrysaora quinquecirrha, Brachionus plicatilis). Despite variation in size and feeding mode, the observed ingestion kernels of all 4 species are surprisingly similar and can therefore be precisely redrawn within the given uncertainties by a single generic function. This match especially supports the validity of the biophysically derived kernel width of $1 / \sqrt{3}$.

Further evidence for a log-normal shape of the feeding kernel can be found in planktonic consumers (e.g. Berk et al. 1977, Frost 1977). A log-normal shape of the prey size-dependence of clearance is also revealed by fish in the absence of light and thus the lack of active prey choice (Holzman \& Genin 2005).

\section{How relevant is capture for size-selectivity?}

Several alternative mechanisms can produce unimodal and skewed dependencies. For example, a right-skewed function of absolute size was derived by Pastorok (1981) for the net energy gained per unit handling time. As in the derivation in this work, Pastorok assumed prey energy content to increase with body volume. In order to arrive at a uni-modal size relationship, Pastorok argued, however, that a larger prey size increases handling time and lowers capture success. Caparroy et al. (2000) proposed allometries in detection range, visibility and swimming velocity to obtain a size dependency of the capture success of Euchaeta elongata (Fig. 3). Visser \& Fiksen (2013) further developed those models by combining (heuristic) size dependencies for handling time, energetic content, and catchability.

In plankton, consumers are in general larger than prey-with a few exceptions such as thecate or palladium feeding dinoflagellates, or a very few scyphomedusae (Hansen et al. 1994, Brose et al. 2006, Wirtz 2012b). As most consumers pursue prey of much smaller size, it is difficult to conceive how capture success can be predominantly controlled by the exact prey size, given that larger individuals are also faster (Greene 1983, Landry \& Fagerness 1988).

The size dependency of capture success will be higher for suspension feeders. Prey with greater motility are more likely to escape capture by suspension feeders (Jakobsen 2002). On the other hand, feeding current velocity can be adjusted to increase rates of suspension capture (Pahlow \& Prowe 2010). For example, fast prey organisms can be trapped by slow feeding currents that have low shear stress ('stealth predation' Raskoff 2002, Colin et al. 2006). To summarize, it is rather improbable that swimming speed and capture success strongly influence the form of both the selectivity and ingestion kernel.

Approaches that start from capture success can be considered complementary to the digestion-based view suggested here. Traits that affect pre-capture performance (e.g. number of chemical or mechanical weapons, swimming speed) and post-capture performance (e.g. dimensions of cutting tools or gut system) may co-evolve in most species. Co-adaptation of feeding traits will ensure that the same target prey size is prioritized through detection, capture, filtration, ingestion and digestion. The co-evolutionary and digestion-based view as suggested here may in particular explain why observed ingestion kernels appear so uniform in Fig. 3 and Fig. 4, albeit these kernels represent consumers with distinct capture strategies and feeding types.
Fig. 4. Brachionus rubens. (A) Clearance rates (relative to maximum) from experiments with food of a specific size (either microalgae or polystyrene spheres). (B) Selective preference on plastic beads $(\diamond)$ and microalgae $(\bullet)$ offered simultaneously. The idealized preference kernel with unity width is drawn as a dotted line. In both cases (A and B), data originate from Rothhaupt (1990) and the neutral kernel with standard deviation of $1 / \sqrt{3}$ is plotted. Horizontal bars: typical size diversity within phytoplankton species populations; vertical bars: SD of clearance measurements
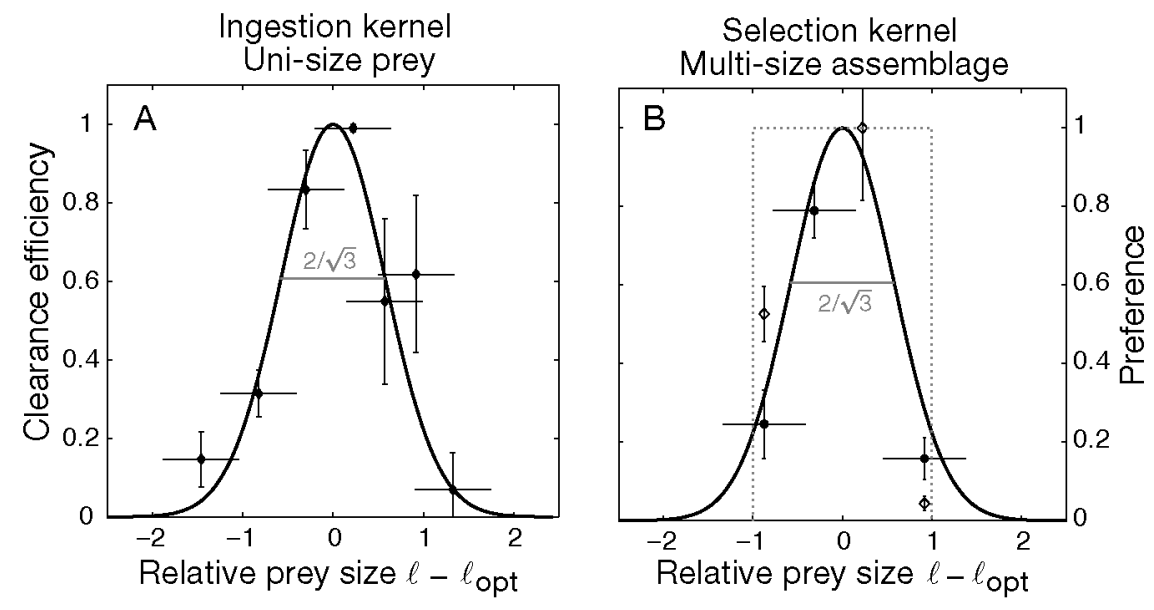


\section{Feeding mode changes}

While digestion is a process common to all zooplankton, mode of prey capture can vary within taxa and can even be altered within single species or individuals. Feeding mode changes in a consumer community reflect both species sorting and behavioral plasticity. A number of jellyfish, copepod, and microzooplankton species can switch between different feeding types, often between ambushing and suspension feeding (Landry 1981, Goldman \& Dennett 1990, Saiz \& Kiørboe 1995). Plasticity in feeding types and related shifts in $\ell_{\text {opt }}$ challenge the theory proposed here. However, the values of $\ell_{\mathrm{opt}}$ for copepods switching between ambushing and suspension feeding turn out to be relatively close. Possibly, the distance between the 2 target sizes $\ell_{\text {opt }}$ of ambushing and suspension feeding is ultimately determined by the universal width of the ingestion kernel. Facultative, omnivorous consumers such as many gelatinous zooplankton species would indeed require a broad ingestion kernel. Gastro-vascular digestion systems of scyphomedusae, which consist of a fractal-like branching network (Russell 1970, Wirtz 2013), may be less affected by 'friction' delays in internal processing as formulated in Eq. (A3) and therefore could have wider ingestion kernels. Limits of a universal ingestion size-width should thus be clarified in future experiments using zooplankton species with plastic feeding modes.

\section{Linking biomechanics to behavior}

The selection kernel characterizes external feeding activity that occurs before ingestion and describes a preference towards certain food item sizes (Fig. 1). Observed size selectivity is functionally well represented as log-normal (Fig. 4). In the underlying feeding experiments with the suspension feeder Brachionus rubens either uni-size or diverse food items were offered (Rothhaupt 1990). Notably, the shapes and widths of the selection and ingestion kernel functions roughly coincide. Two data points from experiments using plastic beads as simulated prey suggest that the rotifer selection kernel may fall between a Gaussian and an idealized rectangular function. In any case, the width equals the biomechanical value of $1 / \sqrt{3}(s=3 / 2)$, which is here termed the neutral width. The reappearance of this neutral value in the size kernel of effective capture indicates a lack of behavioral elements, and a capture mechanism that co-evolved with the digestion apparatus in

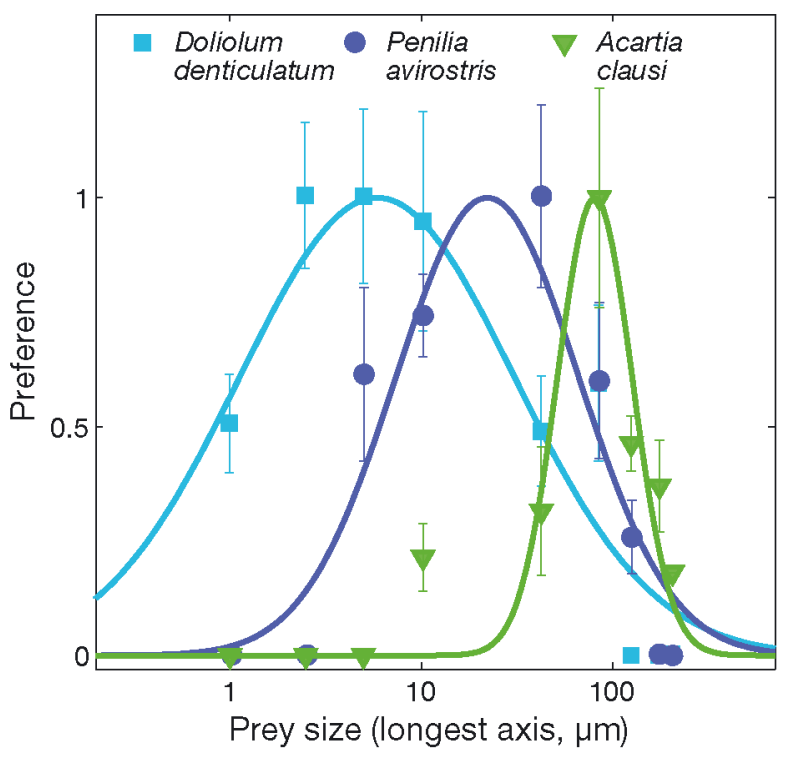

Fig. 5. Observed and theoretically predicted selection kernels $f_{\text {sel }}$ of Acartia clausi $(s=13.03)$, Penilia avirostris ( $s=$ $2.18)$ and Doliolum denticulatum $(s=0.96)$. Means and variances of the log-normal functions are calibrated by leastsquare-root-mean deviation minimization using the data of Katechakis et al. (2004) (for $\ell_{\mathrm{opt}}$ see Table 2). Prey sizes are given as the longest linear extension of the prey organisms

the case of $B$. rubens. In filter feeders, morphological features such as mesh sizes and ciliary distances determine the size window of accessible prey items. These features are, in turn, physically connected to the digestion apparatus. If traits related to capture and digestion co-evolve, then a neutral width defines the maximal prey spectrum that a predator can mechanically capture and digest.

The log-normal form of the selection kernel also persists at enhanced selectivity (Fig. 5). A kernel width smaller than the neutral value is indicative for active manipulation or choices. Behavioral width reduction, for example, explained kernel differences between the obligate suspension feeders Doliolum denticulatum and Penilia avirostris and the facultative forager Acartia clausi in the study of Katechakis et al. (2004). While the 2 first species reveal a kernel width close to the neutral value of $s=3 / 2$, Acartia exhibits a selectivity of $s=13$, which is significantly higher than the universal biomechanical value.

\section{Differential roles for assemblage structure}

Due to their specific definitions, the 2 size dependent functions $I_{\max }$ and $f_{\text {sel }}$ address 2 different questions of plankton-plankton interactions: What can 


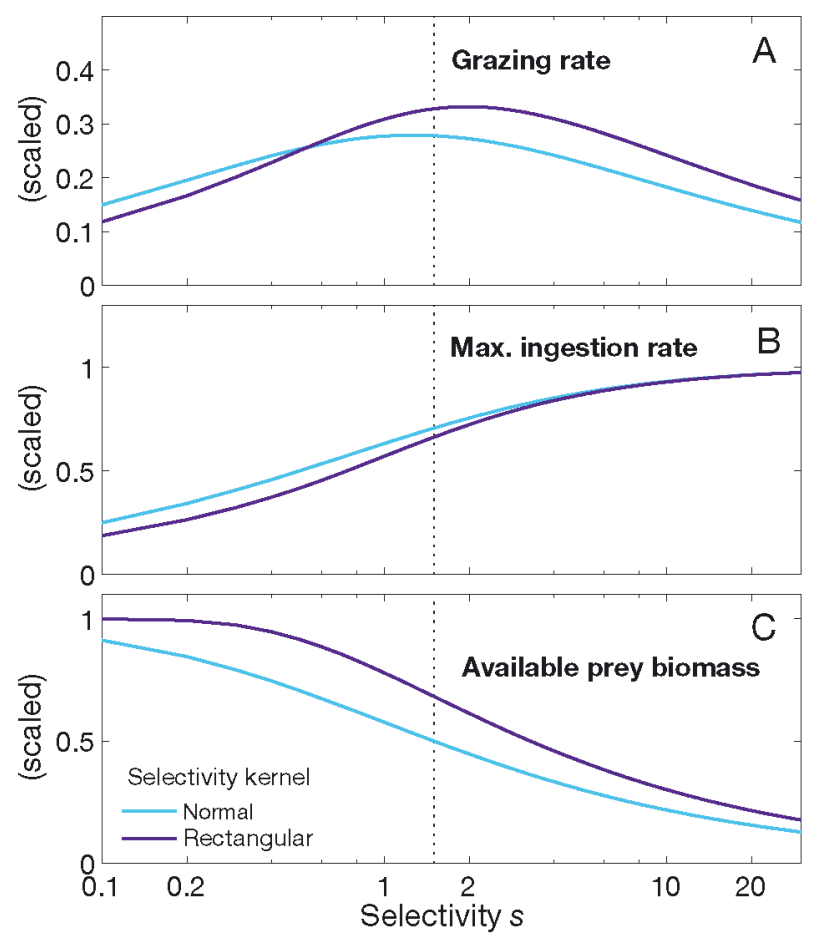

Fig. 6. Three grazing-related functions depending on size selectivity $s$. The integration outcomes based on the usual log-normal feeding kernel (light blue line) are compared to the corresponding results for a rectangular feeding kernel that shares the same first and second order statistics (dark blue line, with $s_{\mathrm{w}}=\sqrt{2 s / 3}$ ). Neutral selectivity of $3 / 2$ is indicated by the dotted line. (A) Integral grazing rate assuming an Ivlev-type dependence: $\bar{I}_{\max }(s) \cdot\left(1-\mathrm{e}^{\left.P(s) / P_{\text {tot }}\right)}\right.$. (B) Grazing performance in terms of the average maximum ingestion rate $\left(\bar{I}_{\max }(s)\right.$, Eq. 5$)$. (C) Concentration of actually preferred and ingested food $P(s)$ (Eqs. 4 \& A7)

consumers eat, and what do they actually eat? Due to these complementary roles, the 2 kernel functions, expressed in terms of their widths, affect the composition of predator and prey assemblages distinctively.

Structure of prey communities, here expressed by mean and variance of the prey size $\left(\tilde{\ell}, \sigma_{\ell}^{2}\right)$ modifies the prey concentration available to a given consumer $(P(s)$ in Eq. 4). This effective prey concentration regulates trophic flow and thereby changes in predator and prey biomass (see also Fig. 6). Mean prey composition, however, does not directly interact with consumer ingestion rate since, surprisingly, the mean maximum ingestion rate $\bar{I}_{\max }$ in Eq. (5) lacks any dependence on the prey-size structure.

Differential effects of the ingestion and selection kernels on prey composition become important in the interpretation of observed patterns in the field. For instance, a substantial top-down predation pressure (high $P$ and $I_{\max }$ ) may induce smaller shifts in the prey community structure than highly selective grazing that occurs at a lower rate. Size dependency in $f_{\text {sel }}$ acts as a strong selective force on prey assemblage and the mean prey size $\tilde{\ell}$. Selective grazing at a flank of the size distribution will shift $\tilde{\ell}$ to higher or lower values depending on the relation between $\ell_{\text {opt }}$ and $\tilde{\ell}$ (Wirtz \& Sommer 2013). In the case when $\tilde{\ell}<\ell_{\mathrm{opt}}$, the prey distribution moves to smaller sizes (Fig. 2).

Predator assemblages both mediate and are in turn influenced by the 2 predator traits feeding width $(1 / s)$ and kernel position $\left(\ell_{\mathrm{opt}}\right)$. Competitive advantages in these characteristics inevitably determine changes in consumer community structure and behavior. In response to the seasonality in prey abundance and size structure, many zooplankton species can effectively reduce prey density at peaks in the size distribution (Richman et al. 1977, Pagano 2008), which is equivalent to sequential shifts in $\ell_{\text {opt }}$. Shifts may also occur in the mean selectivity of predator assemblages. Copepods, for example, show a stronger size preference than do cladocerans (Bogdan \& McNaught 1975, Richman et al. 1977, Peters \& Downing 1984), though this view is not shared by Berman \& Richman (1974). Given a raptorial feeding mode, copepods harvest distinct size classes (Poulet 1978, Vanderploeg 1981). When preferred prey groups decline in abundance, however, specialist grazing becomes more costly and selectivity $s$ should therefore decrease in frequency among individuals, populations, or zooplankton communities. Adaptive changes in $s$ and $\ell_{\text {opt }}$ are indeed found to relate to life history strategies in many zooplankton species (Greene 1983, Berggreen et al. 1988).

\section{Integrated grazing rate}

Effective prey biomass for a given consumer, the mathematical integral of $f_{\text {sel }}$ over all prey size classes, sharply decreases with increasing selectivity as displayed in Fig. 6, and more food is available under a broader preference range (quantified by a small selectivity $s$ ). This trivial relation has been expressed for the first time by the concise, albeit mechanistic, formula Eq. (4). The simplicity of this relation mainly follows from the log-normal shape of $f_{\text {sel }}$.

Prey availability as a function of the trait $s$ implements the conceptual notion of the foraging ratio suggested by Ivlev (1961) or effective prey concentration (e.g. Vanderploeg \& Scavia 1979, Pagano et al. 2003), which were developed originally for foraging fish. Actual ingestion can never use the total amount of energy or organic material in a system, which is here translated to the square root denomina- 
tor in Eq. (4). All natural prey assemblages reveal at least some diversity $\left(\sigma_{\ell}^{2}>0\right)$, and a perfect non-selective predator (with $s=0$ ) seems impossible for morphological reasons. Low selectivity, on the other hand, critically reduces the average maximum ingestion rate $\bar{I}_{\text {max }}(s)$. Only sharp selection narrows the feeding kernel to the most suitable prey size classes (Fig. 6).

$\bar{I}_{\text {max }}$ and effective prey concentration $P$ can be used to estimate the average grazing rate for diverse consumer and prey communities as plotted in Fig. 6. An exact calculation of the mean grazing rate is complicated by the intricate prey-size dependency of feeding activity regulation discussed in Supplement S-II.

\section{Shape and unity width of the selection kernel}

A rectangular-shaped feeding kernel leads to an overall improved food availability compared to a standard log-normal function with the same standard deviation (Fig. 6). In the cumulative calculation of

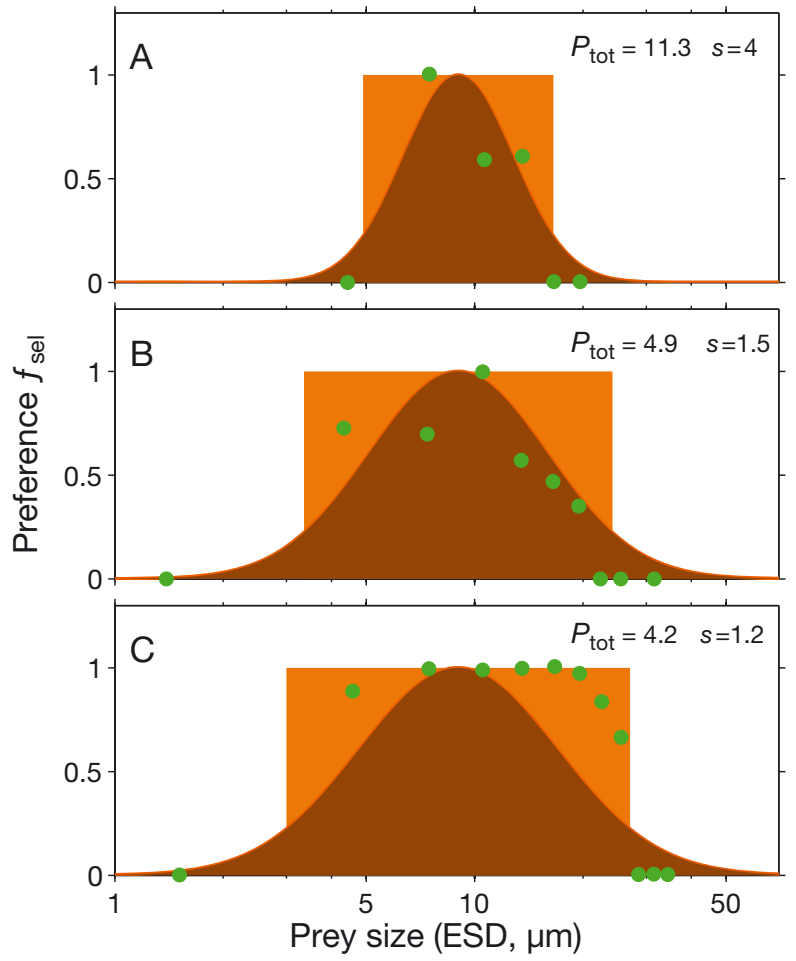

available biomass, the non-normalized version of the rectangular function $\left(f^{\prime}{ }_{\text {sel,w }}\right)$ 'filters' a greater portion of the integrated prey distribution function (cf. different areas below normal and rectangular kernels in Fig. 2 or Fig. 1). $\bar{I}_{\max }$ originates from a different averaging ('weighting') procedure as it represents a consumer property, and thus includes a normalization factor. As a result, the rectangular shape leads to a smaller value of $\bar{I}_{\text {max }}$, and thus a lower performance; the normal selection kernel puts the highest emphasis on the size class where ingestion rate is maximal. However, this effect vanishes at realistic selectivity values $(s \gtrsim 1)$. After combination of the contrasting trends for $\bar{I}_{\max }$ and $P$, the rectangular shape maximizes feeding rates. However, costs of discrimination in terms of processing time are in part embedded in the log-normal shape of the selection kernel. The data compiled in this study were in part compatible with both shapes; the kernels observed by Pagano (2008) for Acartia clausi seem to comply best with an intermediate, but yet smoothed functional form (Fig. 7).

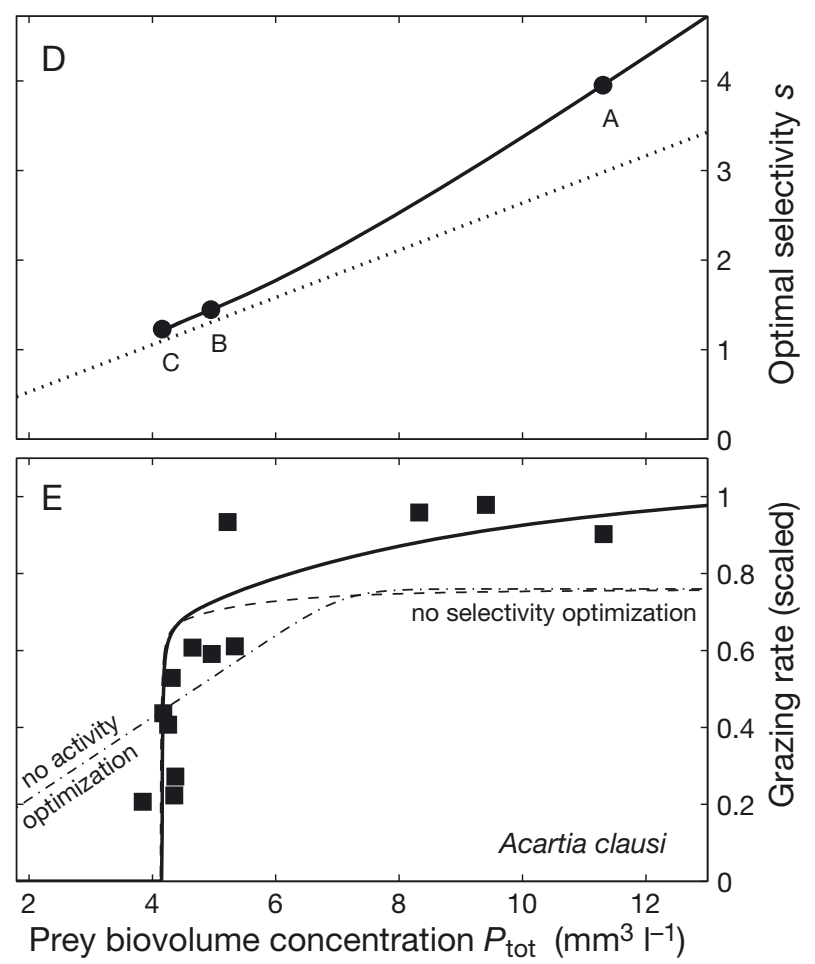

Fig. 7. Acartia clausi. Increase in optimal selectivity with rising prey concentration. (A-C) Relative preference $\left(f_{\text {sel }}\right)$ plotted with a normal (brown) and rectangular (orange) shape; selectivity values $s$ decrease from (A) to (C). Size-class specific preference values measured by Pagano et al. (2003) are plotted as green circles. (D) Optimal selectivities $s$ underlying the preference kernels; values derive from numerically solving Eq. (S3; in Supplement S-III at www.int-res.com/articles/suppl/m507p081_ supp.pdf) (thick continuous line) or from the approximation Eq. (S5) (dotted line). (E) The functional grazing response over the same range in $P_{\text {tot, }}$ both calculated using Eq. (A11) in Supplement S-III (thick, continuous line) and observed by Pagano et al. (2003) (squares). Model variants that lack optimization in selectivity (fixed $s=3 / 2$ ), or in activity (fixed food affinity $A_{z}=$ $0.1 \mathrm{~mm}^{3} \mathrm{l}^{-1} \mathrm{~d}^{-1}$ ) are given as dashed or dot-dashed lines, respectively. ESD: equivalent spherical diameter 
There is an additional theoretical reason for modeling the idealized kernel. Its inverse width $s_{\mathrm{W}}$ functionally corresponds to $s$, the inverse width of the lognormal type $f_{\text {sel }}$. Both functions share equivalent statistical features (i.e., have identical mean and variance) when their widths satisfy the condition $S_{\mathrm{w}}=$ $\sqrt{2 s / 3}$. The rectangular version of the reference lognormal kernel $(s=3 / 2)$ thus has a log-size width of exactly $1\left(s_{\mathrm{W}}=1\right)$. This value is not imposed by any assumption, but emerges from the biophysical constraints of the ingestion kernel.

\section{Trade-off and optimality}

Increased specialization lowers food availability but also improves performance. Combination of these 2 trends produces a trade-off for the regulation of $s$. The resulting unimodality in the integral grazing rate is shown in the center diagram of Fig. 6. A unique selectivity hence optimizes the harvesting rate as a whole.

Under food scarcity, availability becomes more important than performance. Well-fed individuals can afford the costs of selectivity, but poorly fed predators tend to graze less selectively, a pattern which is known for copepods (DeMott 1995). Despite that the selectivity trade-off between availability and performance appears trivial, only very few attempts have been made to devise mechanistic descriptions. For example, Tirok et al. (2011) proposed heuristic trade-off formulations between availability and performance but at the same time found that the functional shape of the trade-off is highly critical for the simulated food-web dynamics.

Due to the unimodal relationship between size selectivity and grazing rate, the comprehensive trade-off representation derived here should be integrated into the framework of optimal foraging theory (Krebs 1978, DeMott 1989). Optimal foraging theory has received some criticism among (zooplankton) ecologists (Pyke 1984, Pierce \& Ollason 1987), but is capable of explaining regulation patterns for specific feeding characteristics (Visser et al. 2009), especially on the plasticity in copepod selectivity (e.g. DeMott 1989, 1995). As outlined in Supplement S-III, optimal size selectivity can be estimated based on a mechanistic response function. Selectivity values predicted by Eq. (S3) or Eq. (S5) correspond well to the observations made by Pagano et al. (2003) for Acartia clausi feeding on natural lake phytoplankton. Depending on total phytoplankton concentration, model and data reveal a reduction in feeding width from 3-30 to 5-17 $\mu \mathrm{m}$ at the transition from food limiting to saturating conditions. This trend can be extended to the experiments of Katechakis et al. (2004) under fully saturated food conditions, in which Acartia clausi concentrated most of its grazing activity to a single size class.

Optimality applies to the other predator traits as well. Feeding activity ( $A_{z}$ in Appendix A-IV) is regulated by many consumers at the behavioral level. Predator body size is considered as fundamental as prey size (Lynch 1977). The kernel position, in this case optimal prey size, can be shown to depend on the predator size and feeding mode (Wirtz 2012b). Adaptive variations in such traits can occur on different time scales, which reflects different mechanisms that include population genetic changes and species sorting due to competition within populations or communities.

\section{CONCLUSIONS}

Mechanistic, realistic, and flexible feeding kernel functions provide an efficient tool for our theoretical approaches to explain food-web structure and dynamics. However, in the course of model formulation it should be clearly stated whether kernels describe the potential to ingest a prey particle of a specific size or the actual ingestion rate under the presence of diverse particles. With the biomechanical derivation of the ingestion kernel and the optimality-based construction of the selection kernel, this work aims to distinguish very distinct sizedependencies in trophic interactions, each associated with different effects on prey and predator community structure. The approach thus gains ground to develop more comprehensive models addressing variable, adaptive grazing strategies in plankton and concomitant effects in pelagic food webs.

Changes in a series of major predator traits modulate the integrated trophic flow intensity through dependencies that have been in part derived in this study. The new formulations come along with mechanistic reasoning, which may in particular evoke future experimental work and hypothesis testing. Further extensions using similar analytical approaches are needed for a fuller treatment of the problems at hand. The ecological richness appearing in aquatic food webs should be captured by simpleand partially novel-variables that are connected through generic mathematical dependencies. 
Acknowledgements. I am grateful to Markus Schartau and Jorn Bruggeman for valuable comments on previous drafts. Nusret Sevinç is acknowledged for helping with data search, and Imke Liffler-Wirtz for the drawing in Fig. 1. Three anonymous reviewers are acknowledged for highly instructive comments. The author was supported by the Helmholtz society via the programme PACES.

\section{LITERATURE CITED}

Armstrong RA (2003) A hybrid spectral representation of phytoplankton growth and zooplankton response: The 'control rod' model of plankton interaction. Deep-Sea Res II 50:2895-2916

Baird ME (2010) Limits to prediction in a size-resolved pelagic ecosystem model. J Plankton Res 32:1131-1146

Banas NS (2011) Adding rich trophic interactions to a sizespectral plankton model: emergent diversity patterns and limits on predictability. Ecol Modell 222:2663-2675

Berggreen U, Hansen B, Kiørboe T (1988) Food size spectra, ingestion and growth of the copepod Acartia tonsa during development: implications for determination of copepod production. Mar Biol 99:341-352

Berk SG, Brownlee DC, Heinle DR, Kling HJ, Colwell RR (1977) Ciliates as a food source for marine planktonic copepods. Microb Ecol 4:27-40

Berman MS, Richman S (1974) The feeding behavior of Daphnia pulex from Lake Winnebago, Wisconsin. Limnol Oceanogr 19:105-109

Boenigk J, Arndt H (2002) Bacterivory by heterotrophic flagellates: community structure and feeding strategies. Antonie Leeuwenhoek 81:465-480

Bogdan K, McNaught D (1975) Selective feeding by Diaptomus and Daphnia. Int Ver Theor Angew Limnol Verh 19: 2935-2942

Broglio E, Saiz E, Calbet A, Trepat I, Alcaraz M (2004) Trophic impact and prey selection by crustacean zooplankton on the microbial communities of an oligotrophic coastal area (NW Mediterranean Sea). Aquat Microb Ecol 35:65-78

> Brooks JL, Dodson SI (1965) Predation, body size, and composition of plankton. Science 150:28-35

Brose U, Jonsson T, Berlow EL, Warren P and others (2006) Consumer-resource body-size relationships in natural food webs. Ecology 87:2411-2417

Bruggeman J (2009) Succession in plankton communities: a trait-based perspective. PhD thesis, Vrije Universiteit Amsterdam

> Caparroy P, Thygesen UH, Visser AW (2000) Modelling the attack success of planktonic predators: patterns and mechanisms of prey size selectivity. J Plankton Res 22: 1871-1900

> Chesson J (1983) The estimation and analysis of preference and its relationship to foraging models. Ecology 64: 1297-1304

Colin SP, Costello JH, Kordula H (2006) Upstream foraging by medusae. Mar Ecol Prog Ser 327:143-155

> Cowan JH, Houde ED (1993) Relative predation potentials of scyphomedusae, ctenophores and planktivorous fish on ichthyoplankton in Chesapeake Bay. Mar Ecol Prog Ser 95:55-65

DeMott WR (1988) Discrimination between algae and artificial particles by freshwater and marine copepods. Limnol Oceanogr 33:397-408

$>$ DeMott WR (1989) Optimal foraging theory as a predictor of chemically mediated food selection by suspension-feeding copepods. Limnol Oceanogr 34:140-154

DeMott WR (1995) Optimal foraging by a suspension-feeding copepod: responses to short-term and seasonal variation in food resources. Oecologia 103:230-240

Frost BW (1972) Effects of size and concentration of food particles on the feeding behavior of the marine planktonic copepod Calanus pacificus. Limnol Oceanogr 17: 805-815

Frost BW (1977) Feeding behavior of Calanus pacificus in mixtures of food particles. Limnol Oceanogr 22:472-491

Fuchs HL, Franks PJS (2010) Plankton community properties determined by nutrients and size-selective feeding. Mar Ecol Prog Ser 413:1-15

Goldman JC, Dennett MR (1990) Dynamics of prey selection by an omnivorous flagellate. Mar Ecol Prog Ser 59: 183-194

Greene CH (1983) Selective predation in freshwater zooplankton communities. Int Rev Gesamten Hydrobiol Hydrograph 68:297-315

> Greene CH, Landry MR (1985) Patterns of prey selection in the cruising calanoid predator Euchaeta elongata. Ecology 66:1408-1416

> Hansen PJ (1992) Prey size selection, feeding rates and growth dynamics of heterotrophic dinoflagellates with special emphasis on Gyrodinium spirale. Mar Biol 114: 327-334

Hansen B, Bjornsen PK, Hansen PJ (1994) The size ratio between planktonic predators and their prey. Limnol Oceanogr 39:395-403

> Hansen B, Wernberg-Møller T, Wittrup L (1997) Particle grazing efficiency and specific growth efficiency of the rotifer Brachionus plicatilis (Muller). J Exp Mar Biol Ecol 215:217-233

> Helmholz H, Johnston BD, Ruhnau C, Prange A (2010) Gill cell toxicity of northern boreal scyphomedusae Cyanea capillata and Aurelia aurita measured by an in vitro cell assay. Hydrobiologia 645:223-234

- Holzman R, Genin A (2005) Mechanisms of selectivity in a nocturnal fish: a lack of active prey choice. Oecologia 146:329-336

Ivlev V (1961) Experimental ecology of the feeding of fishes. Yale University Press, New Haven, CT

Jakobsen HH (2002) Escape of protists in predator-generated feeding currents. Aquat Microb Ecol 26:271-281

Jeschke JM, Tollrian R (2005) Effects of predator confusion on functional responses. Oikos 111:547-555

Jürgens K, DeMott WR (1995) Behavioral flexibility in prey selection by bacterivorous nanoflagellates. Limnol Oceanogr 40:1503-1507

Katechakis A, Stibor H, Sommer U, Hansen T (2004) Feeding selectivities and food niche separation of Acartia clausi, Penilia avirostris (Crustacea) and Doliolum denticulatum (Thaliacea) in Blanes Bay (Catalan Sea, NW Mediterranean). J Plankton Res 26:589-603

Kiørboe T, Saiz E (1995) Planktivorous feeding in calm and turbulent environments, with emphasis on copepods. Mar Ecol Prog Ser 122:135-145

- Kratina P, Vos M, Bateman A, Anholt BR (2009) Functional responses modified by predator density. Oecologia 159: 425-433

Krebs J (1978) Optimal foraging: decision rules for predators. In: Krebs J, Davies N (eds) Behavioural ecology: an evolutionary approach. Blackwell Scientific Publications, Oxford, p 23-63

> Landry M (1981) Switching between herbivory and car- 
nivory by the planktonic marine copepod Calanus pacificus. Mar Biol 65:77-82

Landry M, Fagerness V (1988) Behavioral and morphological influences on predatory interactions among marine copepods. Bull Mar Sci 43:509-529

Litchman E, de Tezanos Pinto P, Klausmeier CA, Thomas MK, Yoshiyama K (2010) Linking traits to species diversity and community structure in phytoplankton. Hydrobiologia 653:15-28

> Lynch M (1977) Fitness and optimal body size in zooplankton population. Ecology 58:763-774

> Manly BFJ, Miller P, Cook LM (1972) Analysis of a selective predation experiment. Am Nat 106:719-736

> Maury O, Faugeras B, Shin YJ, Poggiale JC, Ari TB, Marsac F (2007) Modeling environmental effects on the sizestructured energy flow through marine ecosystems. Part 1: the model. Prog Oceanogr 74:479-499

Moloney CL, Field JG (1991) The size-based dynamics of plankton food webs. I. A simulation model of carbon and nitrogen flows. J Plankton Res 13:1003-1038

Paffenhöfer GA (1984) Does Paracalanus feed with a leaky sieve? Limnol Oceanogr 29:155-160

Pagano M (2008) Feeding of tropical cladocerans (Moina micrura, Diaphanosoma excisum) and rotifer (Brachionus calyciflorus) on natural phytoplankton: effect of phytoplankton size-structure. J Plankton Res 30:401-414

Pagano M, Kouassi E, Saint-Jean L, Arfi R, Bouvy M (2003) Feeding of Acartia clausi and Pseudodiaptomus hessei (Copepoda: Calanoida) on natural particles in a tropical lagoon (Ebrié, Côte d'Ivoire). Estuar Coast Shelf Sci 56: 433-445

Pahlow M, Prowe AEF (2010) Model of optimal current feeding in zooplankton. Mar Ecol Prog Ser 403:129-144

Pastorok RA (1981) Prey vulnerability and size selection by Chaoborus larvae. Ecology 62:1311-1324

> Pearre S Jr (1986) Ratio-based trophic niche breadths of fish, the Sheldon spectrum, and the size-efficiency hypothesis. Mar Ecol Prog Ser 27:299-314

Petchey OL, Beckerman AP, Riede JO, Warren PH (2008) Size, foraging, and food web structure. Proc Natl Acad Sci USA 105:4191-4196

Peters RH, Downing JA (1984) Empirical analysis of zooplankton filtering and feeding rates. Limnol Oceanogr 29:763-784

Pierce GJ, Ollason JG (1987) Eight reasons why optimal foraging theory is a complete waste of time. Oikos 49: 111-118

Poulet SA (1978) Comparison between five coexisting species of marine copepods feeding on naturally occurring particulate matter. Limnol Oceanogr 23:1126-1143

Pyke GH (1984) Optimal foraging theory: a critical review. Annu Rev Ecol Syst 15:523-575

Raskoff K (2002) Foraging, prey capture, and gut contents of the mesopelagic narcomedusa Solmissus spp. (Cnidaria: Hydrozoa). Mar Biol 141:1099-1107

Richman S, Heinle DR, Huff R (1977) Grazing by adult estuarine calanoid copepods of the Chesapeake Bay. Mar Biol 42:69-84

Rothhaupt KO (1990) Differences in particle size-dependent feeding efficiencies of closely related rotifer species. Limnol Oceanogr 35:16-23

Russell FS (1970) The medusae of the British Isles. Cambridge University Press, Cambridge

Saiz E, Kiørboe T (1995) Predatory and suspension feeding of the copepod Acartia tonsa in turbulent environments. Mar Ecol Prog Ser 122:147-158
Sommer U, Stibor H (2002) Copepoda-Cladocera-Tunicata: the role of three major mesozooplankton groups in pelagic food webs. Ecol Res 17:161-174

Suchman CL, Sullivan BK (1998) Vulnerability of the copepod Acartia tonsa to predation by the scyphomedusa Chrysaora quinquecirrha: effect of prey size and behavior. Mar Biol 132:237-245

Swift MC, Fedorenko AY (1975) Some aspects of prey capture by Chaoborus larvae. Limnol Oceanogr 20: 418-425

> Thompson DJ (1975) Towards a predator-prey model incorporating age structure: the effects of predator and prey size on the predation of Daphnia magna by Ischnura elegans. J Anim Ecol 44:907-916

Tirok K, Bauer B, Wirtz K, Gaedke U (2011) Community dynamics driven by feedbacks between functionally diverse trophic levels. PLoS ONE 6:e27357

Troost TA, Kooi BW, Dieckmann U (2008) Joint evolution of predator body size and prey-size preference. Evol Ecol 22:771-799

> Vanderploeg HA (1981) Seasonal particle-size selection by Diaptomus sicilis in offshore Lake Michigan. Can J Fish Aquat Sci 38:504-517

> Vanderploeg HA, Scavia D (1979) Calculation and use of selectivity coefficients of feeding: zooplankton grazing. Ecol Modell 7:135-149

Verity P (1991) Feeding in planktonic protozoans: Evidence for non-random acquisition of prey. J Eukaryot Microbiol 38:69-76

> Visser AW, Fiksen Ø (2013) Optimal foraging in marine ecosystem models: selectivity, profitability and switching. Mar Ecol Prog Ser 473:91-101

- Visser AW, Mariani P, Pigolotti S (2009) Swimming in turbulence: zooplankton fitness in terms of foraging efficiency and predation risk. J Plankton Res 31:121-133

Williams CS, Marshall WM (1938) Duck nesting studies, Bear River migratory bird refuge, Utah, 1937. J Wildl Manag 2:29-48

Williams RJ, Anandanadesan A, Purves D (2010) The probabilistic niche model reveals the niche structure and role of body size in a complex food web. PLoS ONE 5:e12092

Wilson DS (1973) Food size selection among copepods. Ecology 54:909-914

Wirtz KW (2011) Non-uniform scaling in phytoplankton growth rate due to intracellular light and $\mathrm{CO}_{2}$ decline. J Plankton Res 33:1325-1341

> Wirtz KW (2012a) Intermittency in processing explains the diversity and shape of functional grazing responses. Oecologia 169:879-894

> Wirtz KW (2012b) Who is eating whom? Morphology and feeding type determine the size relation between planktonic predators and their ideal prey. Mar Ecol Prog Ser 445:1-12

Wirtz KW (2013) Maximum ingestion rate of planktonic feeders scales with digestive surface area. J Plankton Res 35:33-48

> Wirtz KW, Sommer U (2013) Mechanistic origins of variability in phytoplankton dynamics. Part II: Analysis of mesocosm blooms under climate change scenarios. Mar Biol 160:2503-2516

> Woodward G, Speirs DG, Hildrew AG (2005) Quantification and resolution of a complex, size-structured food web. Adv Ecol Res 36:85-135

Zhou M, Carlotti F, Zhu Y (2010) A size-spectrum zooplankton closure model for ecosystem modelling. J Plankton Res 32:1147-1165 


\section{APPENDIX}

\section{A-I. Derivation of the ingestion kernel}

By definition, the maximum ingestion rate $I_{\max }$ expresses the mass per ingested item $\left(M_{\mathrm{P}}\right)$ over the time to process it $(\tau)$, divided by predator mass $\left(M_{\mathrm{Z}}\right)$.

$$
I_{\max }(D)=\tau(D)^{-1} \cdot \frac{M_{\mathrm{P}}(D)}{M_{\mathrm{Z}}}
$$

Two of the three terms depend on $D$, the equivalent spherical diameter (ESD) of the prey item. First, prey mass $M_{\mathrm{P}}$ is proportional to volumetric density $\rho$ and $D^{3}$,

$$
M_{\mathrm{P}}=\frac{\pi \rho}{6} D^{3}
$$

The second size dependency follows from the sensitivity of $\tau$ to changing prey diameter. Deviations of $D$ from the optimal target diameter inevitably prolong the internal total processing time due to clogging or additional biophysical and chemical preprocessing (e.g. crushing, cutting, production of digestive enzymes). This marginal delay due to additional, prey-size-related processing effort is here formulated as the differential change of $\tau$ with respect to prey diameter changes $(\mathrm{d} \tau / \mathrm{d} D)$. The processing sensitivity $\mathrm{d} \tau / \mathrm{d} D$ should be proportional to a consumer-specific morphological factor (here denoted as $\delta$ ) and $\tau$ :

$$
\frac{\mathrm{d} \tau}{\mathrm{d} D}=\delta \cdot \tau
$$

The factor $\tau$ in Eq. (A3) is again motivated for biomechanical reasons. If handling and digestion already need relatively long periods of time (large $\tau$ ), possible interruptions will take long as well (large $d \tau$ ). Complicated, multi-stage processing and passage through an extended gut increase the risk of clogging or of incomplete digestion. Insertion of the solution of Eq. (A3), which is an exponential increase in single-item processing time with prey size,

$$
\tau=\tau_{0} \mathrm{e}^{\delta \cdot D}
$$

and of Eq. (A2) into Eq. (A1) yields

$$
\begin{aligned}
I_{\max }(D) & =\frac{\pi \rho}{6 \tau_{0}} D^{3} \cdot \mathrm{e}^{-\delta D}=\frac{\pi \rho}{6 \tau_{0}}(D / \mathrm{e})^{3} \cdot \mathrm{e}^{-\delta D+3} \\
& =I_{\max }^{*} \cdot\left(D / D_{\mathrm{opt}}\right)^{3} \cdot \mathrm{e}^{-3\left(D / D_{\mathrm{opt}}-1\right)}
\end{aligned}
$$

$I_{\max }(D)$ becomes maximal at the optimal prey size $D_{\text {opt }}$. We hence have derived the apparent consumer traits $D_{\text {opt }}$ and $I_{\max }^{*}$ as functions of physiological properties, $D_{\mathrm{opt}}=3 / \delta$ and for the maximum value $I_{\max }^{*}=9 \pi \rho / 2 \tau_{0} \mathrm{e}^{3} \delta^{3} \simeq 0.7 \rho / \tau_{0} \delta^{3}$. After transforming from absolute to logarithmic size $(\ell=$ $\left.\log \left(D / D_{0}\right)\right), I_{\max }\left(D / D_{\text {opt }}\right)$ turns to $I_{\max }\left(\ell^{\prime}\right)$ with $\ell^{\prime}=\ell-\ell_{\text {opt }}$. Using the series expansion of the exponential function,

$\log \left(I_{\max } / I_{\max }^{*}\right)=3 \log \left(D / D_{\mathrm{opt}}\right)-3\left(D / D_{\mathrm{opt}}-1\right)=3 \ell^{\prime}-3\left(\mathrm{e}^{\ell^{\prime}-1}\right)$

$$
\approx 3 \ell^{\prime}-3\left(1+\ell^{\prime}+1 / 2 \ell^{\prime 2}-1\right)=3 / 2 \ell^{\prime 2}
$$

and back-transformation to the exponential form yields the log-normal kernel Eq. (1), which agrees well with the one derived in Eq. (A5) (see Fig. 1C).

\section{A-II. Folding the menu (i): food loss by selectivity}

The amount of selected prey follows from the integration over the size distribution $P_{\ell}$ (Eq. S1 in Supplement S-I at www.int-res.com/articles/suppl/m507m081_supp.pdf, with $N=1$ ) times the selection kernel $f_{\text {sel }}^{\prime}$ given by Eq. (3):

$$
P=\int_{-\infty}^{\infty} f_{\text {sel }}^{\prime} P_{\ell} \mathrm{d} \ell=\frac{P_{\text {tot }}}{\sqrt{2 \pi s \sigma_{\ell}^{2}}} \int_{-\infty}^{\infty} \mathrm{e}^{-s\left(\ell-\ell_{\mathrm{opt}}\right)^{2}-(\ell-\tilde{\ell})^{2} / 2 \sigma_{\ell}^{2}} \mathrm{~d} \ell
$$

After using a binomial auxiliary equation,

$$
\begin{aligned}
& s\left(\ell-\ell_{\mathrm{opt}}\right)^{2}+\frac{1}{2 \sigma_{\ell}^{2}}(\ell-\tilde{\ell})^{2}= \\
& \quad\left(s+1 / 2 \sigma_{\ell}^{2}\right)\left(\ell-\ell^{*}\left(\ell_{\mathrm{opt}}, \tilde{\ell}\right)\right)^{2}+\frac{s}{1+2 s \sigma_{\ell}^{2}}\left(\ell_{\mathrm{opt}}-\tilde{\ell}\right)^{2}
\end{aligned}
$$

the analytical integration (with arbitrary size offset $\ell^{*}$ ) yields the closed form of the effective prey concentration in Eq. (4).

The analog result for the rectangular selection kernel is an error function:

$$
P_{\mathrm{w}}=\int_{-\infty}^{\infty} f_{\mathrm{sel}, \mathrm{w}}^{\prime} P_{\ell} \mathrm{d} \ell=P_{\text {tot }} \operatorname{erf}\left(\sqrt{2} S_{\mathrm{w}} \sigma_{\ell}^{-1}\right)
$$

\section{A-III. Folding the menu (ii): ingestion enhancement by selectivity}

In the cumulative integration (Eq. A7) of the total amount of ingested food $P$, the non-normalized form of the selection kernel $f_{\text {sel }}^{\prime}$ is used. $P$ represents a property of the prey field insofar as it is actually used by the predator. However, in the calculation of the effective maximum ingestion rate $\bar{I}_{\max }$ we have to employ the normalized kernel $f_{\text {sel }}$ since $\bar{I}_{\text {max }}$ represents a consumer average.

$$
\begin{aligned}
\bar{I}_{\max } & =\int_{-\infty}^{\infty} f_{\text {sel }}(\ell) I_{\max }(\ell) \mathrm{d} \ell=I_{\max }^{*} \sqrt{\frac{s}{\pi}} \int_{-\infty}^{\infty} \mathrm{e}^{-(s+3 / 2)\left(\ell-\ell_{\mathrm{opt}}\right)^{2}} \mathrm{~d} \ell \\
& =I_{\max }^{*} \sqrt{\frac{s}{s+3 / 2}}
\end{aligned}
$$

Because of the normal shape of the 2 functions $f_{\text {sel }}(\ell)$ and $I_{\max }(\ell)$, the integral Eq. (A10) results in the functionally simple expression (cf. Eq. 5).

\section{A-IV. Mechanistic grazing kinetics}

Grazing kinetics is described using a process-based formulation, which conforms with the distinction between external and internal processing (capturing and digestion) made in this study. The formulation resolves the congruency between external and internal processing through application of operational theory and the introduction of the synchrony parameter $n$ (Wirtz 2012a). This parameter mechanistically determines the effective integral rate of interlinked feeding sub-processes, and this way controls the shape of the grazing rate $G$ as a function of food availability:

$$
G=\bar{I}_{\max } \cdot x \frac{1-x^{n}}{1-x^{n+1}} \quad \text { with } \quad x=\frac{A_{z} \cdot P}{\bar{I}_{\max }}
$$

The ratio between external and internal food processing rates, $A_{z} \cdot P$ and $\bar{I}_{\max }$ respectively, is denoted as $x$. Further discussion of the function can be found in Supplement S-II. 